\title{
“NÃO FICÇÃO É TRADUÇÃO” - UM ENSAIO E UMA CONVERSA COM O AUTOR BRIAN GOEDDE
}

\author{
Lívia de Albuquerque Lakomy \\ Mestre em Escrita Literária de Não Ficção (concentração em Tradução Literária) pela \\ Columbia University \\ Mestranda em Estudos de Tradução pela Universidade de São Paulo (USP) \\ lal2158@columbia.edu
}

\section{RESUMO}

O autor Brian Goedde, então professor na pós-graduação na Universidade de lowa, foi categórico ao escrever e dar o título a um de seus ensaios, apresentado em conferência e publicado em 2007: "Nonfiction is Translation". Neste paper, trazemos o ensaio de Goedde pela primeira vez traduzido e publicado em outro veículo que não a revista em que foi originalmente lançado. Segue-se uma breve entrevista com o autor em que ele explica em mais detalhes alguns pontos levantados pelo texto. Seu trabalho procura levantar uma das grandes intersecções entre a tradução e a não ficção literária que, de certo modo, as colocam em oposição a outras formas de criação literária: o fato de que não devem responder a um "source text", nos termos do próprio autor. Ao buscar um diálogo com os Estudos da Tradução, o autor ilumina ambas as formas e propõe uma nova forma de diálogo entre elas.

Palavras-chave: tradução, não ficção, source text, ensaio, entrevista.

\section{ABSTRACT}

The author Brian Goedde, who was a graduate instructor at the University of lowa at the time, was categoric when titling one of his essays, which he presented at a conference published in 2007: "Nonfiction is Translation." In this paper, we present Goedde's essay, first translated and published in other place but the newspaper where it was released. After the translated essay, we bring a brief interview with the author, where he explains in detail some points raised in his essay. His work is an attempt to illuminate intersections between translation and literary nonfiction which, somehow, puts them in opposition to other forms of creative literacy: the fact that they must not answer to a "source text" - in Goedde's terms. By creating a dialogue with Translation Studies, the author highlights both forms and offers a new possibility of dialog between them.

Key-words: translation, nonfiction, source text, essay, interview. 


\section{Introdução}

Em 2007, Brian Goedde era um instrutor na pós-graduação da Universidade de lowa, Estados Unidos, ministrando oficinas de escrita de não ficção e seminários na área de retórica, além de escrever e publicar seus próprios textos. Como muitos outros professores e praticantes da não ficção, sentia dificuldade em explicar para si mesmo e para seus alunos no que, exatamente, consiste a não ficção, um termo que entrou em voga nos anos 1990 em cursos de escrita para abarcar a literatura feita com base na realidade.

Foi a partir de um convite para participar do congresso da Association of Writers \& Writing Programs (AWP), em 2007, com outros grandes nomes da não ficção contemporânea, que passou a pensar no assunto de maneira mais propositiva. Intitulado "Toward a Theory of Slippery Nonfiction" - algo como "Em direção a uma teoria da elusiva não ficção" - o painel trazia também nomes como Robin Hemley, então diretor do curso de não ficção da Universidade de lowa, um dos mais tradicionais e reconhecidos no mundo, Phillip Lopate, ensaísta e diretor do programa de não ficção na Universidade de Columbia, e David Shields, que além de professor na Universidade de Washington, estava já pensando e planejando seu livro "Reality Hunger: A Manifesto" (2010), que viria a ser algo como um divisor de águas nas maneiras de se pensar as definições da não ficção. Esse painel, portanto, foi em si um divisor de águas na prática americana sobre como se pensar a não ficção, uma vez que por um momento seus principais expoentes se voltaram à procura de uma possível teoria para a prática que faziam todos os dias. Eis a proposta desse painel que originou o ensaio de Goedde: 
Uma certeza: não ficção - de Agostinho a Carson - é literatura. Mas o que isso significa no meio da confusão contemporânea entre o que a forma "pode" ou "não pode" fazer? Nós propomos estruturas teóricas - da psicanálise para a ciência forense, da epistemologia para a resposta do leitor - que, se segurando nas complexidades e possibilidades do gênero, posicionasse (re-posicionasse) o gênero no terreno escorregadio em que sempre esteve, em que sempre estará e em que sempre deve estar (GOEDDE, 2016). (tradução nossa)

Foi com base na sua teoria de que "não ficção é tradução" que Brian Goedde foi convidado a participar do evento. Vale lembrar que Goedde não é propriamente um tradutor no sentido tradicional da palavra, ou seja, não "carrega" textos de uma língua para outra, como coloca no texto que vamos ler. Sua proposta é mais voltada para a ideia de que, sendo a não ficção uma forma de escrita eminentemente prática, ela pode se voltar para a tradução quando precisar se apoiar em bases teóricas mais firmes. Goedde baseia sua ideia no princípio do que chama de "source text" - aplicada tanto ao original da tradução, quanto ao original (vida/realidade/fato) da não fiç̧ão, e logo exemplifica sua teoria com a ideia de "domesticação" e "estrangeirização" aplicada à não ficção.

Logo após o painel, Goedde organizou suas ideias em forma de ensaio assumidamente sua forma preferida para a escrita - e publicou suas conclusões na revista "Creative Nonfiction", a primeira revista a se dedicar exclusivamente à não ficção, sendo também a maior e uma das mais respeitadas no formato.

Cremos, no entanto, que melhor que fornecer uma longa introdução ao seu texto, é deixá-lo falar por si.

Segue-se ao ensaio uma entrevista com Goedde realizada em dezembro de 2018, ou seja, mais de uma década após seu texto ter sido publicado. É durante essa entrevista 
que nos é possível contextualizar, questionar e aprofundar o material proposto pelo autor americano.

\section{A tradução}

\section{"NÃO FICÇÃO É TRADUÇÃO" \\ por Brian Goedde}

Não ficção é tradução, uma palavra que literalmente significa "carregar através". Onde os tradutores carregam um texto de um idioma para outro, os escritores de não fiç̧ão levam os "textos" dos mundos ao nosso redor e dos mundos dentro de nós para o texto feito de palavras na página.

Estes dois transportes são mais complicados do que eles parecem à primeira vista. Se todas as línguas funcionassem da mesma maneira, o trabalho do tradutor seria fácil. Mas não é isso que acontece, então cada escolha de palavra na tradução está sobrecarregada com todas as conotações, denotações, históricos de uso e nuances de significado que o tradutor possa imaginar e/ou pesquisar em ambos os idiomas e em ambas as culturas. Na não ficção existem não só as complexidades da linguagem para se navegar, mas também os contornos da memória, da experiência, da percepção, da subjetividade - de cada consideração existencial e epistemológica que o escritor possa imaginar e/ou pesquisar. (Claro, você poderia imaginar que não há complexidade em escrever não ficção, mas você também poderia "imaginar" que as palavras ahora e vaco rimam da mesma maneira que as palavras now e cow rimam.) 
Felizmente para nós, a tradução já tem sua complexidade reconhecida há muito tempo e respondeu a tudo isso com teoria, muita da qual pode ser aplicada à não ficção. Para explicar, primeiro alguns básicos da tradução:

O ato - e arte - da tradução acontece ao carregarmos através aquilo que é comumente chamado de "source text", ou texto de partida (o poema, história, peça ou ensaio em um idioma), para o "target text", ou texto de chegada (esse mesmo poema, história, peça ou ensaio em outro idioma). Se a tradução é uma "boa" tradução, geralmente quer dizer duas coisas: a escrita no "target text" é fluida, rítmica, econômica, etc. - todas as qualidades da boa escrita - e que um aspecto importante do texto de origem, geralmente o conteúdo, mas às vezes a forma, foi preservado o mais fielmente possível. É difícil fazer as duas coisas.

Isso leva a dois outros termos importantes na teoria da tradução: "domesticação" e "estrangeirização". Domesticação é quando você prioriza a experiência de leitura de texto de chegada em detrimento do conteúdo do texto de origem. Por exemplo, em vez de traduzir uma expressão diretamente - uma personagem chinês diz, "ele é meu Zhuge Liang" - você encontra algo em inglês americano que tem um significado semelhante: "ele é meu braço direito". Essa escolha "domestica" o texto de origem, tornando a expressão americanizada, esquecendo a referência a esse conselheiro militar da dinastia Han. Se você estrangeirizasse essa frase, você iria manter a referência histórica, específica da cultura, e colocaria um ponto de interrogação na cabeça do leitor, que então tem que descobrir quem era Zhuge Liang ou buscar algumas pistas no contexto sobre o que essa frase significa.

A diferença entre a domesticação e a estrangeirização foi caracterizada pelo tradutor e teórico do século XIX Friedrich Schleiermacher como ou 1) uma perturbação 
para o leitor por uma questão da integridade do texto de partida, ou 2) uma perturbação no texto de partida por uma questão de conforto do leitor. A não ficção também enfrenta este dilema.

A não ficção é uma espécie de tradução no sentido de que primeiro faz a afirmação que existe um "source text" de experiência vivida no "mundo real" - como quer que o autor queira definir isso. (Por uma questão de tempo e, provavelmente, da sua paciência, aqui eu tenho que fazer um desvio a afastar-me da beira do abismo de "o que é real e o que é verdade". Decida por você mesmo; ainda assim você vai estar traduzindo.) Nessa tradução, o escritor de não ficção faz as escolhas de domesticar ou estrangeirizar.

Por exemplo: vamos dizer que eu estou escrevendo um ensaio sobre o meu amigo Nate. Se eu permanecer completamente fiel ao texto fonte, eu gostaria de entrevistar o Nate e transcrever suas citações de maneira exata, mantendo até mesmo suas frases incompletas e o uso particular de locuções como "cara", "meu", "você me entende." Roteiristas de documentários utilizam essa técnica para capturar uma personagem através da preservação dos padrões de fala particulares. Nate ia ser deixado como ele é, o leitor teria uma experiência estranha e o texto de chegada iria, assim, ser estrangeirizado. Se eu quero completamente domesticar o Nate, não iria entrevistá-lo; eu comporia todas as suas declarações para que o leitor tivesse na página um alto-falante totalmente fluido, coerente, rítmico, econômico, etc. Não seria nem um pouco o Nate que existe no mundo real (porque na verdade, ninguém fala assim), mas o leitor poderia seguir pela página sem problemas. Livros de memórias geralmente usam essa abordagem. Se eu quero fazer algo no meio do caminho, posso fazer o que faz um jornalista: entrevistar Nate para capturar suas palavras e a forma como ele as usa, mas completar suas frases e the dar um verniz de eloquência. 
Ou - e isso é o que acontece mais realisticamente em ambas as artes da tradução e da não-ficção - a decisão de domesticar ou estrangeirizar o texto de partida vem linha por linha, palavra por palavra.

Nomear e qualificar todos esses termos não faz o trabalho de transportar Zhuge Liang ou Nate menos complicado. Mas pode oferecer a quem faz esse transporte uma forma sofisticada para chegar ao seu destino, uma sofisticação que se torna necessária dado o poder que quem faz esse transporte possui. Os termos "domesticar" e "estrangeirizar" têm ecos de política porque o tradutor é, em essência, um mediador influente não só dos poemas, histórias, peças de teatro e ensaios, mas também dos autores e culturas que os informaram e originaram.

O escritor de não ficção tem um poder semelhante. O corolário mais óbvio é na escrita de viagens, mas em qualquer gênero de não ficção - mesmo o mais solipsista - o escritor tem controle sobre a representação, caracterização e expressão dos povos e culturas que compõem a fonte. Esse tipo de poder também deve dar origem a uma filosofia sobre como melhor transportá-lo.

Brian Goedde é professor adjunto de não ficção literária na Universidade de lowa. Seus ensaios já foram publicados no The New York Times, Resonance e Writing on the Edge, entre outras publicações. "Não ficção é tradução" foi apresentado pela primeira vez em 2007 na Association of Writers \& Writing Programs (AWP, 2007).

\section{Entrevista}

Entrevista com Brian Goedde, realizada em 27/11/2017 
Esta entrevista foi traduzida do inglês, editada e condensada para melhor compreensão.

Pergunta: Como surgiu a ideia para este ensaio, "Não Fiç̧ão É Tradução"?

Brian Goedde: Fez inicialmente parte de um painel no AWP. A ideia por trás de tudo era criar uma espécie de quadro teórico para a não ficção. Dar umas ideias para escritores de não ficção, para que a gente não fique apenas sentindo o nosso caminho pelo escuro. Que podemos ter uma teoria, que podemos criar algumas orientações. Foi onde entrou a tradução. Existe um corpo de teoria tão grande na tradução e serve tão bem [para a não ficção].

Outra pessoa nesse painel foi uma escritora chamada Bonnie Rough e ela olhou para a ciência forense e como ela é parecida com o que estamos falando [na não ficção]. Como, por exemplo, se há testemunhas para um crime e o que elas fazem é descrever o criminoso e, em seguida, a desenhista cria uma imagem com essas descrições em mente, é algo semelhante. Há um sério conjunto de orientações a se considerar. O que eles desenham tem algumas sérias implicações legais. Então, enfim, só vendo como eles fazem seu trabalho, aqueles artistas forenses, foi um outro tipo de conjunto teórico de orientações, acho que eu poderia dizer.

Pergunta: Então, basicamente o que você procurava era uma base teórica para escrever não fiç̧ão, e é algo realmente muito difícil, não temos muito disso. Uma coisa que eu queria perguntar: você tem sua própria definição do que é a não fiç̧ão? 
BG: Do que é a não fiç̧ão? É um termo tão vago. O termo que eu prefiro é o ensaio, em razão de sua tradição literária, do que ele sugere e do que ele faz. Você vai para o dicionário de Inglês da Oxford e a definição é de uma tentativa, ou um empreendimento. Então eu gosto de usar o termo ensaio.

Quando me sento para escrever, acho que estou mais na tradição dos ensaístas do que na tradição dos escritores de não ficção, porque ainda não sei o que isso significaria para mim como escritor praticante. Talvez seja mais claro - é mais evidente - quando escrevo, digamos, jornalismo. Há uma clara tradição de jornalismo e também diretivas e uma ética jornalística. Então isso é muito claro, mas quando eu me sento e penso "eu sou um escritor de não ficção criativa", é como tentar alcançar algo que não está lá.

Pergunta: Você não acha que poderia ser benéfico, liberador?

BG: Creio que pode ser. Se funciona para você em termos de processo criativo, então eu não te impediria de ser publicada em uma revista chamada "Creative Nonfiction", por exemplo. Mas acho que o que nunca tive muito claro é o que esse termo significa ou deveria dizer.

Mas desculpe, acho que perdi o fio da meada da sua primeira pergunta, se eu tenho uma definição? Não tenho mesmo. E nas minhas próprias aulas, quando eu estou ensinando escrita criativa, estou mais interessado em olhar para as possibilidades que existem para cada pessoa como escritor criativo. Poesia, por exemplo, as muitas formas que ela pode tomar. Isso é mais o que me interessa em termos de gênero. Menos essa coisa do que é e o que não é. 
Pergunta: E o que você acha do termo "não fiçcão"?

BG: Digamos que... não me agrada. Porque eu gosto de pensar sobre a escrita como ensaios. Eu não gosto do termo, na verdade. É engraçado porque ele entrou na nossa linguagem, definitivamente na nossa linguagem acadêmica. No próximo semestre eu vou ensinar algo como "Inglês Alguma Coisa: Não Ficção". Então, vou ter que parar e pensar, "agora eu tenho que lidar com isso!" Mas vai ser nas primeiras semanas quando vou apenas dizer "olha, eu prefiro que a gente fale sobre o ensaio como nossa tradição, nos mostrando um conjunto das possibilidades do que podemos fazer". Considerando que a não ficção, quando eu escrevi o ensaio que você encontrou... não foi muito tempo após aquela polêmica toda com James Frey e seu livro de memórias, lembra? "A Million Little Pieces" e tudo o mais, com suas partes inventadas. Então houve bastante debate no programa de não ficção em que eu estava, em lowa, muita discussão sobre o que se pode fazer como um escritor de não ficção em termos de representação. Coloquei alguns exemplos no ensaio.

Se alguém está falando com você, como eu estou falando com você agora, se você for transcrever isso em sua própria escrita, e mesmo se você for me citar, se você for ser absolutamente fiel você deve manter todos os meus ummms e ahhhs e frases incompletas, certo? Se você quer me fazer parecer um burro você vai incluir isso! (risos)

Pergunta: Não é esse o objetivo! (risos)

BG: Espero que não! Todos os jornalistas limpam as citações em uma entrevista. Você não representa tudo com $100 \%$ de fidelidade, sílaba por sílaba, porque então perde a marca do que você pretendia fazer, que era capturar o entrevistado em suas próprias 
palavras de forma respeitosa. Se você realmente capturar cada sílaba, você vai fazer a pessoa parecer boba ou inarticulada. Com esse tipo de coisas em mente, que é o que me atraiu para a tradução, eu pensei "olha, aqui está uma teoria sobre por que você vai tomar essas decisões". Não era apenas ser desleixado, não era apenas ser manipulador, mas é o que poderia ser chamado de "domesticar" o texto de origem para que ele saia de forma mais fluida e respeitosa na página impressa.

Pergunta: Você então estaria evocando, em tradução, Schleiermacher. Venuti também escreveu sobre isso. Algumas pessoas que acreditam em estrangeirizar e talvez os próprios teóricos também prefiram. No seu ensaio, porém, você fala sobre essa ser uma decisão caso a caso, e você menciona também a "tensão" que isso traz para a escrita. Escrever é criar tensão, certo? Você quer que o leitor continue lendo. Você estava pensando em domesticar versus estrangeirizar também nesse sentido?

BG: Isso foi muito bem colocado. Não sei se escrevi isso ou não, mas me parece ótimo! Criar uma certa tensão no texto é o que você quer, e então parte disso vem de você dar ao leitor acesso ao texto. Em um sentido muito prático, o que queremos como escritores? Queremos leitores. Quanto mais leitores, melhor. Dar aos leitores acesso ao texto cria parte dessa tensão nos termos da domesticação. Quanto à estrangeirização, como conseguir isso no texto a partir da experiência vivida? Hum... Eu não sei... Meu ensaio foi uma tentativa em si. O que você acha? Gostaria de saber o que você pensa sobre tudo isso. 
Pergunta: Pensando por meio de Schleiermacher, talvez sua intenção fosse expandir o idioma alemão naquele período. Ele queria deixá-lo estrangeiro para então torná-lo algo próprio. E talvez, especialmente quando falamos de representação, estrangeirizar poderia ser mais verdadeiro?

BG: Acho que essa é uma ideia fantástica. Como ao citar formas diferentes de inglês, diferentes dialetos. Suponho que a questão realmente se resume em como é a melhor forma de respeitar a fonte ("source text"), porque se alguém fala em, vamos supor, Black American English - e muitos escritores têm enfrentado essa pergunta escrevendo em ficção e não fiç̧ão - e alguém como Zora Neale Hurston toma a decisão de escrever o diálogo dessa forma. Para mim, como um americano branco e leitor do século XXI, parece muito estrangeirizado. Acabei de ler Hurston uns meses atrás e tive de ler trechos em voz alta para ouvir e reconhecer algumas palavras. Então isso é um gesto muito estrangeirizante que ela está fazendo com essa fonte. E faz parte do cânone! Eu acho que neste momento todos nós reconhecemos - embora tenha sido extremamente controverso quando ela fez isso - que ela fez isso com o maior respeito pelo inglês dos negros americanos. Mostra, ao ponto de que você articula, um respeito para com a fonte e para com a língua e melhora a nossa língua. Então isso é ótimo. Que grande tensão, essa.

Pergunta: Você usa uma palavra da tradução para a não ficção, o termo "source". Não tinha visto a palavra usada assim, exceto no jornalismo, mas não para representar algo como a "realidade" ou o fato/experiência que dá origem ao texto. Isso foi coisa sua ou inspirada por alguém? 
BG: Acho que é coisa minha. Não me lembro de ouvi-lo de outra fonte. Eu estava me lembrando da época... Você vai falar com minha esposa, Emily, certo? Ela estava no programa de tradução e eu no de não ficção, e na verdade tínhamos acabado de nos conhecer. Eu estava aprendendo várias coisas sobre tradução por meio dela e fazendo conexões pelo trabalho que ela fazia - que os tradutores fazem - porque não sou um tradutor, exceto pelo fato de que eu sou um escritor de não ficção e não ficção é tradução e tudo mais...

Eu ficava olhando por cima do ombro dela para ver que tipo de material que ela estava estudando e me lembro de ver esse conceito e pensar que, sim, é a mesma situação para escritores de não-ficção e ensaístas em termos de recordar um evento e renderizá-lo em termos de frases e parágrafos.

Também, no que diz respeito àquele breve ensaio sobre não ficção e tradução... havia evasões, dando realmente voltas em torno de questões filosóficas muito essenciais, o que é uma limitação do projeto, até mesmo do espaço e do tempo que tive. Mas o que eu acho que o mais valioso pensar sobre esse assunto seria: realmente esclarecer o sentido que dou da experiência vivida como um "source text" e o que isso significa.

Nós achamos que esse "source text" é como um livro publicado, algo como "está aqui, da página um até a página sei lá quanto", como um objeto. Mas claro que isso não é verdade. O texto fonte é um objeto vivo e há uma multiplicidade de significados. É uma coisa aberta, não é uma coisa fechada. Como a memória de uma experiência vivida.

Há um material enorme sobre o qual não vou conseguir falar, então eu espero que [outros] o façam, mostrando que um "source text" de uma tradução é tão fluido, multifacetado, complicado, e assim por diante, quanto uma experiência vivida para uma escritor de não-ficção. 


\section{Pergunta: Algum último comentário?}

BG: Só mesmo que eu não gosto de definir os gêneros, acho que temos muito a aprender uns com os outros, criativamente até. Vamos olhar para os outros tipos de escrita criativa em outras formas a fim de melhorar a nossa própria.

\section{Considerações finais}

A análise realizada permite a observação de que a poesia retrata a diferença de classes e as consequências disso em um país como o Brasil. Através de sua poesia-cidadã, Vaz realiza uma denúncia sobre privilégios e justiça. O poema "Os Miseráveis", por meio de enunciados que se opõem, desvenda uma das maiores mazelas brasileiras: a impunidade. Assim, os personagens apresentam finais distintos, apesar de ambos terem praticados atos ilícitos: Vítor "apodrece penitente", enquanto Hugo "enriquece livremente". Isso revela, portanto, os privilégios de classe, algo tão presente em uma sociedade classista como a brasileira.

Para que esses significados oferecidos pelo texto sejam alcançados pelo leitor, é necessária uma leitura competente. Desse modo, corroboramos a necessidade de que o texto seja assimilado em sua completude, perpassando o sentido de língua (compreensão) e alcançando o sentido de discurso (interpretação).

Portanto, entendemos que a língua deva ser trabalhada em sala de aula como uma prática social dotada de significados. É imprescindível a interseção entre o estudo de língua portuguesa e o estudo de literatura. Por meio da leitura proficiente de textos literários, o aluno, além de adquirir a língua, será introduzido em temas políticos, sociais, 
econômicos, emocionais, contribuindo para o reconhecimento de seu papel enquanto sujeito histórico.

Acreditamos, portanto, que os textos literários, enquanto objetos de estudo, trazem a possibilidade de o docente realizar um trabalho no qual as três competências de leitura evocadas por Charaudeau sejam desenvolvidas, favorecendo a reflexão e a construção de uma criticidade, formando, de fato, leitores competentes.

\section{Referências}

AWP - Association of Writing Programs. 2007 Conference. F125. Toward a Theory of Slippery Nonfiction. (Phillip Lopate, Abigail Thomas, Bonnie J. Rough, Robin Hemley, David Shields, Brian Goedde). Ementa disponível em:

<https://www.awpwriter.org/application/public/pdf/conference/2007/2007Schedule.pdf >. Acesso em: 28 mar. 2018.

GOEDDE, Brian. Nonfiction is translation. Disponível em:

<https://www.creativenonfiction.org/brevity/craft/craft_goedde.htm>. Acesso em: 01 out. 2016.

SHIELDS, David. Reality hunger: a manifesto. Penguin: 2010.

Recebido em 15 de março de 2018.

Aceito em 10 de abril de 2018. 